\title{
A Comparison of the Antioxidative and Anti-Diabetic Potential of Thermally Treated Garlic, Turmeric, and Ginger
}

\author{
Fredreana Hester, Martha Verghese*, Rajitha Sunkara, Shantrell Willis, Lloyd T. Walker \\ Food and Animal Sciences Department, Alabama A \& M University, Normal, AL, USA \\ Email: *martha.verghese@aamu.edu
}

How to cite this paper: Hester, F., Verghese, M., Sunkara, R., Willis, S. and Walker, L.T. (2019) A Comparison of the Antioxidative and Anti-Diabetic Potential of Thermally Treated Garlic, Turmeric, and Ginger. Food and Nutrition Sciences, 10, 207-219. https://doi.org/10.4236/fns.2019.102016

Received: November 22, 2017

Accepted: February 16, 2019

Published: February 19, 2019

Copyright (c) 2019 by authors and Scientific Research Publishing Inc. This work is licensed under the Creative Commons Attribution International License (CC BY 4.0).

http://creativecommons.org/licenses/by/4.0/

\section{c) (i) Open Access}

\begin{abstract}
Spices have been used for centuries for food preservation, flavors, and medicinal properties. Research suggests that garlic, turmeric, and ginger contain potent antioxidants that may prevent and/or delay chronic diseases such as cancer, diabetes, and heart disease. Heat treatment of spices may potentially increase antioxidative activity by modifying the inherent chemical structure of potent antioxidative compounds within spices. The purpose of this study was to determine the impact of thermal treatment of garlic, ginger, and turmeric on total phenolic content (TPC), total flavonoid content (TFC), 2,2-diphenyl-1-picrylhydrazyl (DPPH) scavenging activity, ferric reducing antioxidant potential (FRAP), trolox activity (TEAC), lipase, a-amylase, and a-glucosidase inhibition. Conventional stovetop heating of selected spices was performed followed by methanolic and aqueous extractions ( 1 - 5 minutes; $70^{\circ} \mathrm{C}-130^{\circ} \mathrm{C}$ ). Overall methanolic extracts had higher phytochemical, antioxidative, and anti-diabetic potential. However, aqueous garlic extracts exhibited higher phytochemical and antioxidative potential over methanolic garlic extracts. The highest TPC for aqueous garlic extracts was observed at 1 minute (14.11 mg GAE/g) while methanolic garlic extracts at 1 minute were significantly lower (1.72 mg GAE/g). Methanolic turmeric extracts had highest TPC at 5 minutes $(28.55 \mathrm{mg} \mathrm{GAE} / \mathrm{g})$. Time and temperature influenced antioxidant activity in the spices. Turmeric and ginger (methanolic extracts) resulted in higher percent inhibition of DPPH radical with an increase in time (5 minute) turmeric (86.9\%) and ginger $(79.09 \%)$ at $7.9 \mathrm{mg} / \mathrm{mL}$ concentration. The results of this study revealed both solvent and time for thermal treatment of spices influenced antioxidative potential as determined using DPPH and FRAP assays. Therefore, the use of thermal application on spices presents promise in potentiating the antioxidant content and thereby their potential health promoting properties. Spices are utilized in the U.S. food industry and
\end{abstract}


increasing their use as a natural antioxidant preservative and flavoring agent may have beneficial impact in food product development.

\section{Keywords}

Turmeric, Garlic, Ginger, Thermal Treatment, Antioxidant

\section{Introduction}

Phytochemicals are bioactive substances of plants that have been associated in human health in the protection against chronic degenerative diseases [1]. Before the advancement of modern medicine, spices and herbs were used as therapeutic agents to prevent and treat a variety of ailments serving as folk medicine. Research shows that plants contain bioactive compontents, phytochmicals which may aid in disease prevention due to the abundance of antioxidants, phenolic acids, and other health promoting compounds [2] [3] [4]. Diabetes is a chronic disease that is heavily influenced by individual's diet and lifestyle. Research suggest that consumption of fruits, vegetables, and spices may lead to lower incidence of the development of diabetes [5] [6] [7] [8]. Garlic, turmeric, and ginger (TGG) have been used for centuries within folk medicine due to their health promoting properties attributing to various phytochemcials and antioxidants such as curcuminoids, shogaols, and allicin [9]. Culinary uses of spices generally involve some forms of thermal processing for the production of food products prior to their consumption. Thermal processing is the most widely used process technology within the food industry, to ensure microbiological safety of food [10]. Thermal application of food results in both physical and chemical modulations which may have benefical or detrimential effects. It is cricial that phytochemcials within food maintain bioactive stability in order to impart health promoting properties. Research suggests that thermal application on plant substances could increase antioxidant capacity [10] [11] [12]. Therefore, the objective of this study is to evaluate the effect of thermal processing on the phytochemical, antioxidative, and enzymatic inhibition of garlic, turmeric, and ginger.

\section{Materials and Methods}

\section{Reagents}

The following chemicals were purchased from Sigma Aldrich Chemical Co. (St. Louis, MO, USA) and Fisher Scientific (Pittsburgh, PA, USA): Folin-Ciocalteau reagent, catechin, galic acid, Trolox (6-hydroxy-2,5,7,8-tetramethychroman-2-carboxylic acid), TPTZ (2,4,6-tripyridyl-s-triazine), DPPH (2,2-diphenyl-1-picrylhydrazyl), ABTS (2,2'-azinobis (3-ethylbenzothiazoline-6-sulfonic acid), pancreatic lipase, pNB $(2,4$, p-nitrophenyl butyrate substrate, soluble starch, dinitrosalicyclyic acid, p-nitrophenyl- $\alpha$-D-glucopyranoside, dinitrosalicylic acid, $\alpha$-amylase (porcine pancreatic), and $\alpha$-glucosidase (yeast).

Spice Preparation 
Garlic (Allium sativum), ginger (Zingiber officinale), and turmeric (Curcuma longa) powders were purchased from Monterey Bay Spice Company, (Watsonville, CA). Spices were subjected to direct heat treatments for experimentation. Direct heat-treated turmeric, ginger, and garlic powders were conducted by stovetop toasted for $1\left(70^{\circ} \mathrm{C}-100^{\circ} \mathrm{C}\right), 2.5\left(70^{\circ} \mathrm{C}-114^{\circ} \mathrm{C}\right)$, and $5\left(70^{\circ} \mathrm{C}-130^{\circ} \mathrm{C}\right)$ minute time points. The times and temperatures were chosen as not to burn the spices, but a notable change in browning would occur. The times and temperatures were selected Post-toasting $5 \mathrm{~g}$ of turmeric, garlic, and ginger were added to $50 \mathrm{~mL}$ of $80 \%$ methanol or deionized water and allowed to stir for 2 hours. The mixture was stirred for $2 \mathrm{hr}$ on an orbital shaker then centrifuged (Sorvall Legend XTR; Thermo-Scientific, West Palm Beach, FL, USA) at $3000 \mathrm{xg}$ for 20 mins. The supernatant was collected, filtered and evaporated (Bushi, Zurich, Switzerland) to dryness. The extraction was reconstituted with solvent and stored at $-80^{\circ} \mathrm{C}$ until further analysis.

Determination of Phytochemical Content and Antioxidative Potential

Total Phenolic Content (TPC)

Total phenolic content for spice extracts was determined following the Folin-Ciocalteau (FC) method with slight modifications [13]. Briefly $12.5 \mu \mathrm{l}$ of sample and $50 \mu \mathrm{l}$ of $\mathrm{ddH}_{2} \mathrm{O}$ was added to 96 well plate accordingly. Next $12.5 \mu \mathrm{l}$ of Folin-Ciocalteau reagent was added and allowed to mix for 5 minutes. Lastly $125 \mu \mathrm{l}$ of $7 \% \mathrm{NaCO}_{3}$ was added and the plate was shaken for 90 minutes before being read at room temperature at $750 \mathrm{~nm}$ versus a blank of $\mathrm{ddH}_{2} 0$ using a microplate reader (Synergy HT, BioTek instrument Inc., Vermont, USA). Gallic acid was used as standard for determining phenolics. The results are expressed as means (mg GAE/100g) \pm SEM for three replicates.

Total Flavonoid Content (TFC)

Determination of total flavonoid content in extracts was determined using an aluminum chloride colorimetric assay as described by Marinova et al. [14] with

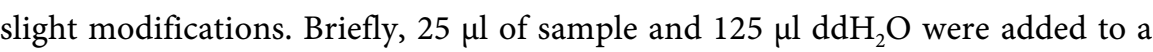
96 well plate followed by the addition of $7.5 \mu \mathrm{l}$ of $5 \% \mathrm{NaNO}_{2}$ and allowed to stand for 5 minutes. After 5 minutes, $15 \mu \mathrm{l}$ of $10 \% \mathrm{AlCl}_{3}$ was added to the mixture and incubated at room temperature for 5 minutes. Lastly, $50 \mu \mathrm{l}$ of $1 \mathrm{M}$ $\mathrm{NaOH}$ was added followed immediately by $25.5 \mu \mathrm{l}$ of $\mathrm{ddH}_{2} \mathrm{O}$. The absorbance was read at $510 \mathrm{~nm}$ using a microplate reader (Synergy HT, BioTek instrument Inc., Vermont, USA) against a blank prepared with $\mathrm{ddH}_{2} \mathrm{O}$. A standard curve for flavonoids was developed using catechin $(0.02-0.4 \mathrm{mg})$ and the results are expressed as means $(\mathrm{mg} \mathrm{CE} / 100 \mathrm{~g}) \pm \mathrm{SEM}$ for three replicates.

$D P P H$ (2, 2-diphenyl-1-picrylhydrazyl) Assay (DPPH)

$\mathrm{DPPH}$, a stable radical was used to measure total antioxidant potential of the selected extracts, using a method suggested by Brand-Williams et al. [15] with slight modifications. Briefly, a $0.1 \mathrm{mM}$ solution of DPPH in $80 \%$ methanol was used. For the reaction, $40 \mu \mathrm{l}$ of sample was added into a 96 well plate followed by $200 \mu \mathrm{l}$ of DPPH solution. For the control, $40 \mu \mathrm{l}$ of water and $200 \mu \mathrm{l}$ of DPPH was 
used for the assay. Absorbance was read at 0,30,60, and 90-minute time points using a microplate reader (Synergy HT, BioTek instrument Inc., Vermont, USA). Radical scavenging ability was expressed as decrease in the percentage of DPPH. The results are expressed as means \pm SEM for three replicates. Calculations for DPPH were conducted as follows:

$$
\% \mathrm{DPPH}=\left(A_{\text {control }}-A_{\text {sample }} / A_{\text {control }}\right) \times 100 .
$$

\section{Ferric Reducing Antioxidant Potential (FRAP)}

Total FRAP of extracts were assessed according to the protocol described by Benzie and Strain [16] with slight modifications. Briefly, $10 \mu \mathrm{l}$ of sample, $30 \mu \mathrm{l}$ of ddH20 and $30 \mu$ of FRAP reagent were combined and read at an absorbance of $593 \mathrm{~nm}$ using a microplate reader (Synergy HT, BioTek instrument Inc., Vermont, USA). The FRAP reagent was made fresh and heated to $37^{\circ} \mathrm{C}$ prior to use. The FRAP reagent consisted of $10 \mathrm{mM}$ 2,4,6-tri (2-pyridyl)-s-triazine (TPTZ) in $40 \mathrm{mM} \mathrm{HCl}, 20 \mathrm{mM}$ ferric chloride $\left(\mathrm{FeCl}_{3}-6 \mathrm{H}_{2} 0\right)$, and $300 \mathrm{mM}$ acetate buffer ( $\mathrm{pH}$ 3.6). The change in absorbance was compared to a ferrous sulfate standard curve $(0.1 \mathrm{mM}-1 \mathrm{mM})$. The results are expressed in $\mu \mathrm{mol}$ of $\mathrm{Fe}^{2+} / 100 \mathrm{~g}$ for three replicates.

\section{Trolox Equivalent Antioxidant Capacity (TEAC)}

TEAC of extracts was assessed according to protocol suggested by Miller et al. [17] with slight modifications. Briefly, a $7 \mathrm{mM}$ ABTS (2, 2-azino-bis (3-ethylbenzothiazoline-6-sulfonic acid)) radical solution was prepared and left at room temperature in the dark for 12 - 16 hours to develop. After the ABTS radical developed, it was then diluted with ethanol to get an absorbance of $0.7 \pm$ 0.025 at $734 \mathrm{~nm}$. For assay, $10 \mu \mathrm{L}$ of sample and blank were added to a 96 well plate. Next, $290 \mu \mathrm{L}$ of diluted ABTS radical was added. The absorbance was read at $734 \mathrm{~nm}$ for six (6) minutes at one (1) minute intervals. A trolox curve $(0.02$ $\mathrm{mM}-0.5 \mathrm{mM}$ ) was used as a standard to calculate the TEAC of each sample. The results are expressed as means \pm SEM for three replicates.

Inhibition of lipid and carbohydrate enzymes

Lipase inhibition

Lipase inhibition by extracts was determined using DNPB as a substrate by Mosmuller et al. [18] with modifications. Spice extracts, lipase and potassium phosphate buffer ( $\mathrm{pH} 7.2$ ) with $0.1 \%$ tween $80 \%$ was added to the samples followed by incubation for 1 hour at $30^{\circ} \mathrm{C}$. After incubation, $25 \mathrm{mM}$ of pNB $(2,4$ p-nitrophenylbutanoic acid) was added and incubated again for 5 min at $30^{\circ} \mathrm{C}$ and absorbance was read at $405 \mathrm{~nm}$. The inhibitory activity of lipase was calculated as follows:

$$
\operatorname{Inhibition}(\%)=\frac{\text { Absorbance }(\text { control })-\text { Absorbance }(\text { sample })}{\text { Absorbance }(\text { control })} \times 100
$$

$\alpha$-amylase inhibition

The ability of spice extracts to inhibit a-amylase activity was assessed according to a protocol adapted by Apostolidis et al. [19] with modifications. Briefly 50 
$\mu \mathrm{L}$ of sample $(0.55-11.11 \mathrm{mg} / \mathrm{mL})$ and $50 \mu \mathrm{L}$ of enzyme were added to a 96 well plate and mixed for 10 minutes at $25^{\circ} \mathrm{C}$. The plate was then read at an absorbance of $540 \mathrm{~nm}$. Post-incubation $50 \mu \mathrm{l}$ of $1 \%$ starch solution in $0.02 \mathrm{M}$ sodium phosphate buffer, $\mathrm{pH} 6.9$ was added and incubated at $25^{\circ} \mathrm{C}$ for 10 minutes. Absorbance was read at $540 \mathrm{~nm}$ using a microplate reader (Synergy HT, BioTek instrument Inc., Vermont, USA). The reaction was stopped with the addition of $100 \mathrm{ul}$ of dinitro-salicylic acid color reagent (DNSA) and the absorbance was measured at $540 \mathrm{~nm}$. The plate was then steamed for 5 minutes and allowed to cool to room temperature for 20 minutes. The final reading was taken at an absorbance of $540 \mathrm{~nm}$. The determination of \% inhibition was calculated as follows:

$$
\operatorname{Inhibition}(\%)=\frac{\text { Absorbance }(\text { control })-\text { Absorbance }(\text { sample })}{\text { Absorbance }(\text { control })} \times 100
$$

$\alpha$-glucosidase inhibition

$\alpha$-glucosidase inhibition by extracts was assessed according to a protocol adapted by Apostolidis et al. [19] with modifications. Briefly, in a 96 well plate, 50 $\mu \mathrm{L}$ of phosphate buffer ( $50 \mathrm{mM}$; pH 6.8), $10 \mu \mathrm{l}$ of $\alpha$-glucosidase $(1 \mathrm{U} / \mathrm{ml})$, and 20 $\mu \mathrm{L}$ of sample extract $(0.17-1.67 \mathrm{mg} / \mathrm{mL})$ were added and incubated for 5 minutes at $37^{\circ} \mathrm{C}$. Following incubation, $20 \mu \mathrm{L}$ of $1 \mathrm{mM}$ p-nitrophenyl-a-D-glucopyranoside solution (PNPG) in $0.1 \mathrm{M}$ phosphate buffer ( $\mathrm{pH}$ 6.9) was added and incubated at $37^{\circ} \mathrm{C}$ for $30 \mathrm{~min}$. Lastly, $50 \mu \mathrm{L}$ of sodium carbonate $(0.1 \mathrm{M})$ was added and read at an absorbance of $405 \mathrm{~nm}$ using a microplate reader (Synergy HT, BioTek instrument Inc., Vermont, USA). Determination of \% inhibition was calculated as follows:

$$
\text { Inhibition }(\%)=\frac{\text { Absorbance }(\text { control })-\text { Absorbance }(\text { sample })}{\text { Absorbance }(\text { control })} \times 100
$$

\section{Statistical Analysis}

Data are presented as means \pm SEM. In addition, statistical tests used include ANOVA to determine significant differences among treatment groups, using Tukey's studentized range test. The statistical analysis was conducted using SAS software 9.1

\section{Results \& Discussion}

Figure 1 shows the total phenolic (GAE/g) content (TPC) of garlic, turmeric, and ginger extracts (control (unheated), 1, 2.5, and 5 min thermal treatment). The TPC ranged from $0.90 \mathrm{mg}$ GAE/g (garlic control methanolic extract)to $32.61 \mathrm{mg} \mathrm{GAE} / \mathrm{g}$ (turmeric $5 \mathrm{~min}$ methanol extract).In turmeric extracts, heating of spices resulted in TPC to increase by $161 \%, 138 \%$ and $204 \%$, respectively compared to the control (unheated).

Ginger extracts displayed a similar trend where methanolic extracts had higher TPC with the exception of ginger (2.5 minutes), where aqueous extracts had significantly $(p \leq 0.05)$ higher TPC compared to the control. The application of 


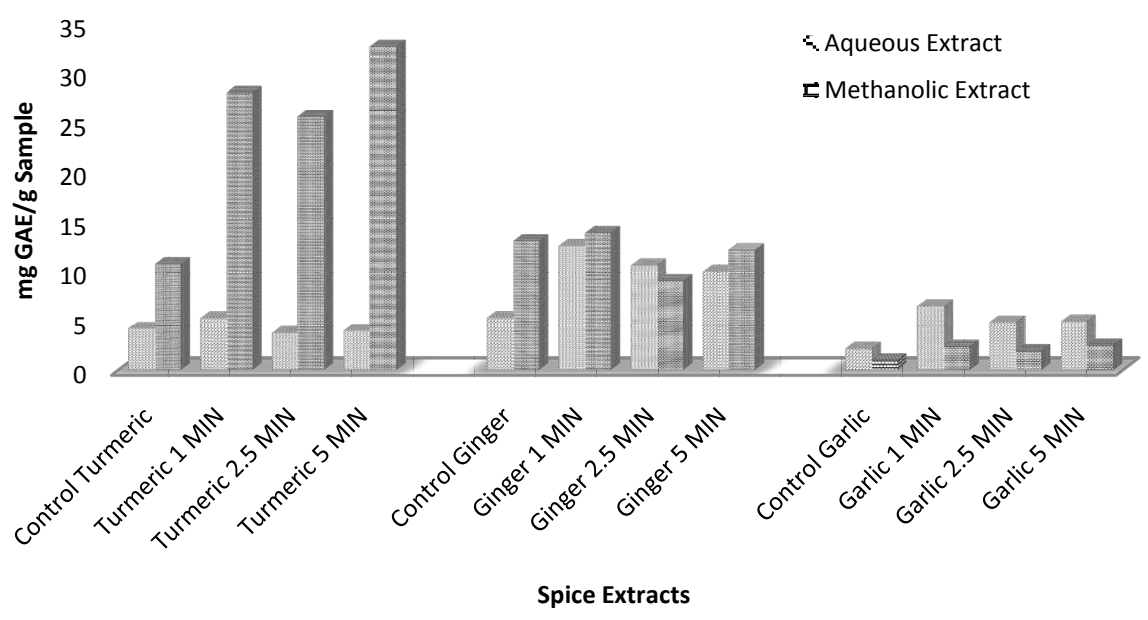

Figure 1. Total phenolic content of all spice extracts, Abbreviations: GAE = Gallic acid equivalents.

heat significantly $(p \leq 0.05)$ increased TPC in all aqueous extracts compared to aqueous control. Unlike both turmeric and ginger, aqueous extracts of garlic had significantly $(p \leq 0.05)$ higher TPC compared to methanolic extracts. An inverse trend was seen between methanolic and aqueous extracts. For thermally treated aqueous extracts, as treatment time increased, there was a decrease in TPC with no changes seen after $2.5 \mathrm{~min}$. However, in thermally treated garlic (methanolic extracts), as time increased, there was a higher TPC seen with no significant differences amongst samples. The presence of fat soluble phenolic compound, phydroxybenzoic acid, could account for the increase in TPC of methanolic extracts of garlic [20]. Both methanolic and aqueous control samples contained significantly $(p \leq 0.05)$ lower TPC compared to their thermally treated counterparts.

Overall, the TPC was higher in turmeric samples compared to both ginger and garlic, while garlic samples displayed the lowest TPC. When comparing extracts, turmeric and ginger displayed a five-fold and two-fold higher TPC compared to garlic. Research [21] [22] [23] reported similar trends in TPC with garlic being lower than that of turmeric and ginger. This may be attributed to the presence of curcuminoids, which are more stable than the organo-sulfur compounds such as allicin found in garlic, which are highly volatile.

Figure 2 displays the TFC of spice extracts [heated spices $(1,2.5$, and $5 \mathrm{mi}-$ nutes) and non-heated (control)]. The highest TFC was seen in the methanolic turmeric control extract $(8.32 \mathrm{mg} \mathrm{CE} / \mathrm{g})$ and the lowest in aqueous garlic control extract $(0.174 \mathrm{mg} \mathrm{CE} / \mathrm{g})$. Overall, ginger extracts exhibited the highest amount of flavonoid content with the exception of turmeric control-methanolic $(8.32 \mathrm{mg}$ $\mathrm{CE} / \mathrm{g})$ and garlic $1 \mathrm{~min}$-methanolic $(4.92 \mathrm{mg} \mathrm{CE} / \mathrm{g})$. Thermal application to garlic resulted in a significantly $(p \leq 0.05)$ higher TFC with 1 min treated samples showing the highest TFC (4.92 mg CE/g). However, there was a significantly ( $p$ $\leq 0.05$ ) lower TFC in extracts heated at 2.5 and $5 \mathrm{~min}$. The main phytochemical compounds within garlic allicin, diallyl-disulphide and diallyl-trisulphide, which are inherently volatile therefore as heat increased there, was destruction and/or 


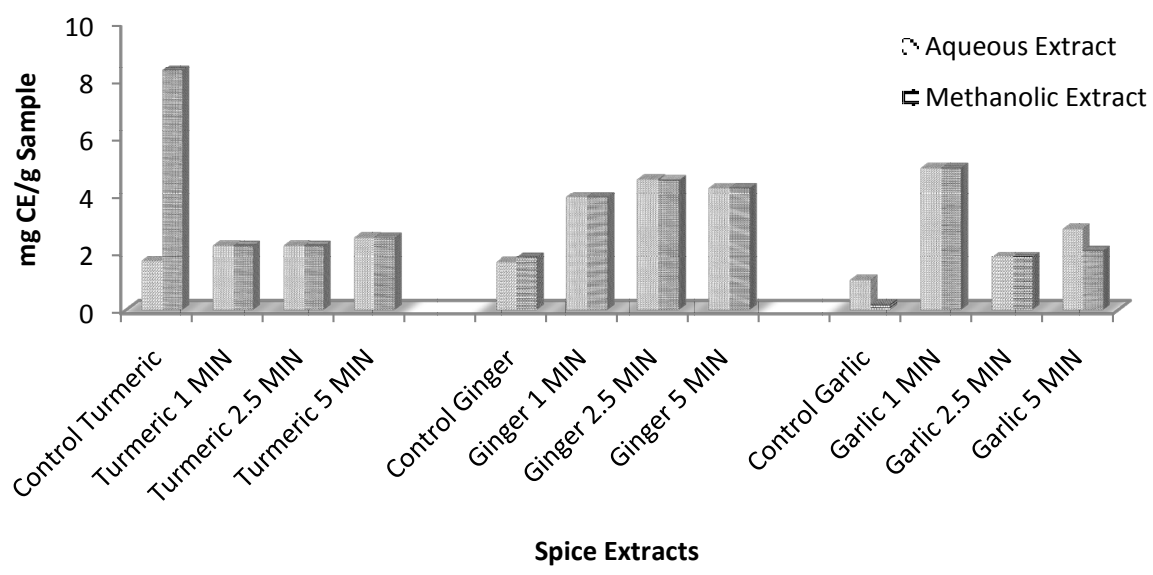

Figure 2. Total flavonoid content of all spice extracts, Abbreviations: $\mathrm{CE}=$ Catechin equivalents.

loss of compounds [24]. Unlike TPC of the spices, thermal application did not significantly impact TFC when comparing solvents.

Total antioxidant capacity as measured by Ferric Reducing Antioxidant Potential (FRAP) (which shows the reducing ability) and Trolox (which shows Trolox equivalence) is shown in Table 1. Both turmeric and ginger (methanolic extracts) exhibited higher reducing ability with increasing thermal application time, with $2.5 \mathrm{~min}$ resulting in highest FRAP activity for turmeric $(100.31 \mu \mathrm{mol}$ $\left.\mathrm{Fe}^{2+} / \mathrm{g}\right)$ and ginger $\left(162.1 \mu \mathrm{mol} \mathrm{Fe}{ }^{2+} / \mathrm{g}\right)$. Aqueous extracts for garlic displayed the highest FRAP activity at $5 \mathrm{~min}\left(28.47 \mu \mathrm{mol} \mathrm{Fe} e^{2+} / \mathrm{g}\right)$. For the Trolox assay methanolic extracts for all spices exhibited significantly higher TE. Additionally the application of heat resulted in a significant reduction in TE all control methanolic samples were significantly higher than heat treated spices.

The radical scavenging ability of spices (control and thermally treated 1 - 5 min) methanolic and aqueous extracts is shown in Table 2. Both turmeric (methanol) and ginger (methanol) extracts exhibited $\mathrm{IC}_{50}$ at lower concentrations compared to their aqueous (extracts) counterparts. This is supported by higher fat-soluble phytochemical content (both TPC and TFC) in methanolic samples. Garlic (aqueous) extracts exhibited the opposite trend, having lower $\mathrm{IC}_{50}$ concentrations. When comparing extracts, ginger extracts were able to scavenge and reduce the radical DPPH at lower concentrations $(0.25 \mathrm{mg} / \mathrm{mL}-2 \mathrm{mg} / \mathrm{mL})$ compared to both garlic $(0.5 \mathrm{mg} / \mathrm{mL}-4 \mathrm{mg} / \mathrm{mL})$ and turmeric $(0.2 \mathrm{mg} / \mathrm{mL}-10$ $\mathrm{mg} / \mathrm{mL})$.

The percent inhibition of $\alpha$-amylase by thermally (1, 2.5, $5 \mathrm{~min}$ ) treated and control extracts is shown in Figure 3. Control samples for all spices resulted in a significantly ( $p \leq 0.05$ ) higher percent $\alpha$-amylase inhibition compared to thermally treated spice extracts with the highest inhibition seen in methanolic ginger extracts (58.88\%). The reduction in $\alpha$-amylase inhibition of thermally treated extracts compared to control may be attributed to alterations, loss, and/or damage of active phytochemicals present. Similar modulation of carbohydrate metabolizing enzymes post-thermal application was seen in Oboh, G., Akinyemi, A, 
Table 1. FRAP and Trolox Activity of garlic, turmeric, and ginger extracts.

\begin{tabular}{ccccc}
\hline & \multicolumn{2}{c}{ FRAP $\left(\mu \mathrm{mol} \mathrm{Fe}^{2+} / \mathrm{g}\right)$} & \multicolumn{2}{c}{ TEAC $(\mu \mathrm{M})$} \\
\hline & Water & Methanol & Water & Methanol \\
\hline Control Turmeric & 32.709 & 13.71 & 118.6 & 205.57 \\
Turmeric 1 MIN & 1.44 & 87.82 & 6.27 & 37.13 \\
Turmeric 2.5 MIN & 1.39 & 100.31 & 5.005 & 70.65 \\
Turmeric 5 MIN & 1.895 & 98.225 & 5.06 & 68.13 \\
Control Ginger & 92.83 & 19.23 & 116.79 & 119.04 \\
Ginger 1 MIN & 13.375 & 140.255 & 10.96 & 45.79 \\
Ginger 2.5 MIN & 14.42 & 162.105 & 10.56 & 49.28 \\
Ginger 5 MIN & 13.35 & 138.03 & 8.71 & 59.26 \\
Control Garlic & 27.91 & 3.77 & 7.93 & 54.48 \\
Garlic 1 MIN & 13.16 & 1.605 & 6.8 & 1.29 \\
Garlic 2.5 MIN & 17.525 & 1.625 & 13.36 & 1.32 \\
Garlic 5 MIN & 28.47 & 1.99 & 5.703 & 3.09 \\
\hline
\end{tabular}

Table 2. Radical scavenging ability of garlic, turmeric, and ginger extracts.

\begin{tabular}{ccccc}
\hline & \multicolumn{2}{c}{ Water } & \multicolumn{2}{c}{ Methanol } \\
\hline & $\geq$ IC 50 (mg/ml) & \% INHIBITION & $\geq$ IC 50 (mg/ml) & \% INHIBITION \\
\hline Control Turmeric & N/A & 31.38 & 2 & 54.24 \\
Turmeric 1 MIN & 10 & 68.98 & 0.2 & 55.5 \\
Turmeric 2.5 MIN & 10 & 67.63 & 0.2 & 57.26 \\
Turmeric 5 MIN & 10 & 59.36 & 0.2 & 56.47 \\
Control Ginger & 10 & 53.28 & 1 & 82.68 \\
Ginger 1 MIN & 0.5 & 54.99 & 0.25 & 94.24 \\
Ginger 2.5 MIN & 0.5 & 52.46 & 0.25 & 94.03 \\
Ginger 5 MIN & 2 & 57.1 & 0.25 & 80.96 \\
Control Garlic & N/A & 18.47 & N/A & 14.43 \\
Garlic 1 MIN & N/A & 46.3 & 1 & 51.64 \\
Garlic 2.5 MIN & 0.5 & 52.46 & N/A & 48.79 \\
Garlic 5 MIN & 1 & 57.1 & 4 & 55.38 \\
\hline
\end{tabular}

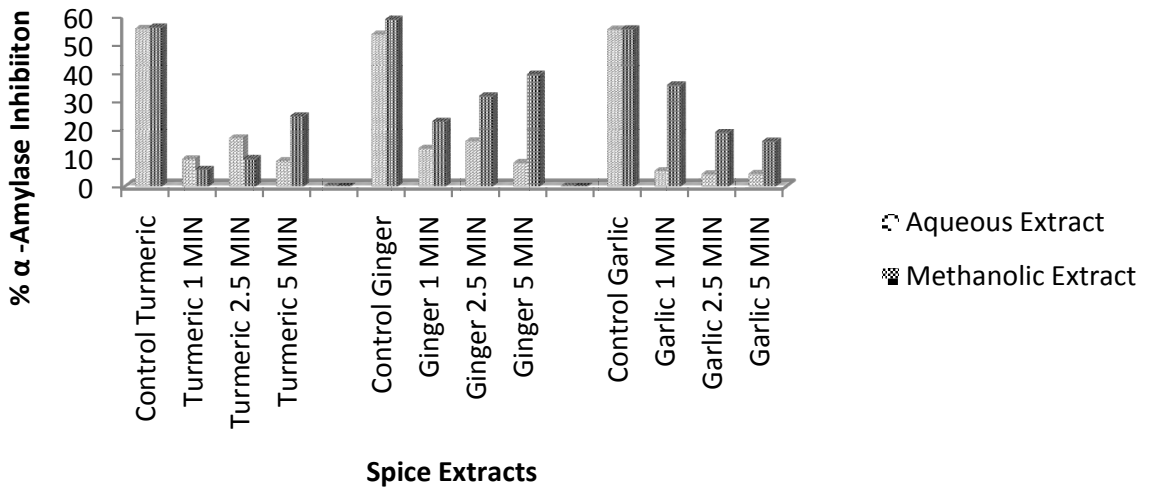

Figure 3. a-Amylase Inhibition of Spice Extracts. 
\& Ademiluyi, A. [25]. In turmeric (methanol) and ginger (methanol) samples, with an increase in heating time there was an $(p \leq 0.05)$ increase in percent inhibition of $\alpha$-amylase. Ginger and turmeric are botanically related as members of the Zingiberaceae family, [26] therefore this supports the similar trends seen in $\alpha$-amylase inhibition. While the reverse was seen in garlic (methanol), as thermal time increased there was a decrease in percent inhibition.

The percent inhibition of $\alpha$-glucosidase by thermally (1,2.5, and $5 \mathrm{~min}$ ) and non-thermally treated spices is shown in Figure 4. Garlic (2.83\% - 55.45\%) extracts showed the highest percent inhibition of $\alpha$-glucosidase with ginger $(1.41 \%$ - 9.52\%) extracts showing the lowest inhibition. Overall, thermal treatment of spices resulted in an increase in inhibition of $\alpha$-amylase. This was the reverse response as seen in $\alpha$-glucosidase inhibition, where thermal treatment showed a significant decrease in percent inhibition. However, similar to $\alpha$-amylase, incubation with both turmeric (methanol) and ginger (methanol) resulted in an increase in percent inhibition with an increase in thermal treatment time. While the reverse was seen in garlic (methanol), as thermal time increased there was a reduction in percent inhibition of $\alpha$-glucosidase.

Carbohydrate metabolizing enzymes, $\alpha$-amylase and $\alpha$-glucosidase are essential enzymes within the digestive system leading to the cleavage of dietary starch compounds into maltose and glucose [27]. Research [27] [28] [29] has reported that both $\alpha$-amylase and $\alpha$-glucosidase inhibitors from plant phytochemicals may regulate absorption of carbohydrate and be used to treat type 2 diabetes. In this study, the ability of garlic, ginger, and turmeric's to inhibit $\alpha$-amylase and $\alpha$-glucosidase inhibition was measured.

Research has suggested the potential of bioactive compounds from plants in the inhibition of both $\alpha$-amylase and $\alpha$-glucosidase. Nickavar and Yousefian [30] reported ethanolic garlic extracts $(11.8-36.0 \mathrm{mg} / \mathrm{ml})$ to have a $13.93 \%-54.96 \% \alpha$-amylase inhibitory activity. All heat-treated garlic extracts displayed comparable $\alpha$-amylase inhibition ranging from $44 \%-55 \%$ inhibition. Today arcarbose, miglitol, and voglibose are common $\alpha$-amylase and $\alpha$-glucosidase enzyme inhibitors [2]. With increasing reports demonstrating the effectiveness of medicinal plants to delay carbohydrate hydrolysis, plant sources such as garlic and turmeric show potential to serve as natural alternatives.

The inhibition of lipase by thermally $(1,2.5,5 \mathrm{~min})$ and non-thermally treated turmeric, ginger, and garlicis shown in Figure 5. Overall, garlic extracts exhibited the highest lipase inhibition followed by ginger and turmeric. Lipase inhibition by garlic is attributed to the presence of phenolic acids and sulfur containing compounds. Salicylic acid, a phenolic acid found in garlic has been suggested as a lipase inhibitor [31]. Additionally, garlic compounds, allinin, allicin, and ajoene have also been reported to have hypolipidemic effects [32] [33] [34]. Additionally, within ginger and garlic curcuminoids and gingerones have been suggested to exhibit hypolipidemic effects [26]. 


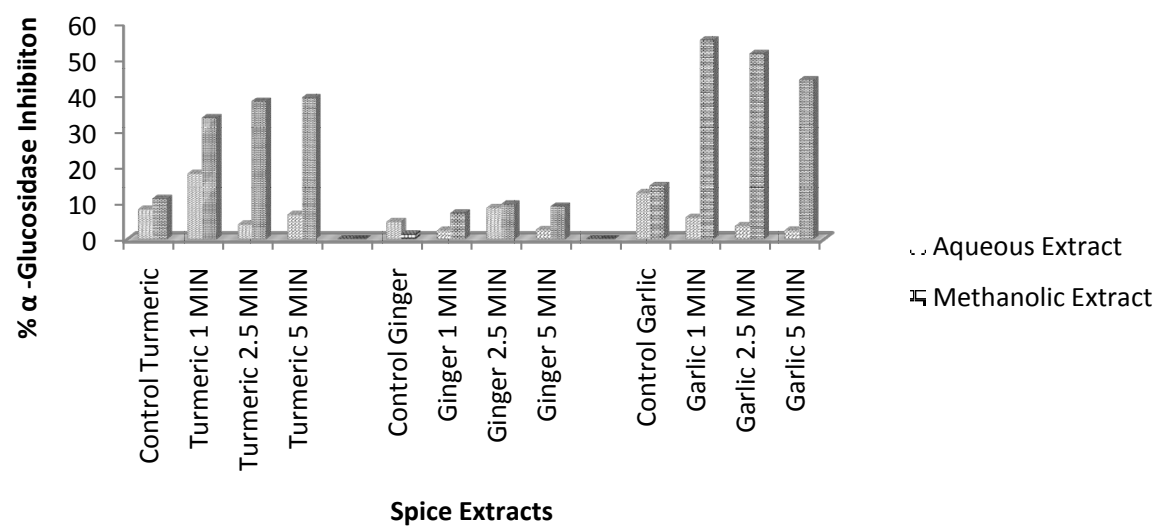

Figure 4. A-glucosidase inhibition of spice extracts.

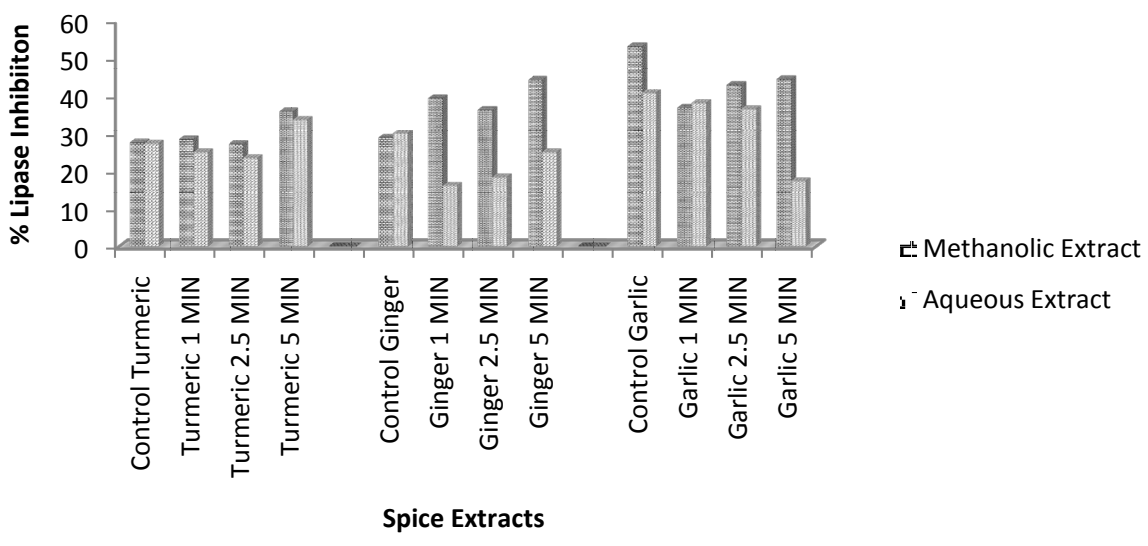

Figure 5. Lipase inhibition of spice extracts.

\section{Discussion}

Total phenolic content (TPC), total flavonoid content (TFC), 2, 2-diphenyl-1-picrylhydrazyl (DPPH) scavenging activity, ferric reducing antioxidant potential (FRAP), trolox activity (TEAC), lipase, $\alpha$-amylase, and $\alpha$-glucosidase inhibition of thermally treated spices (TGG) were measured. Phytochemical content and antioxidative activity was dependent on solvents used for extraction. Our results displayed a similar trend of methanolic extracts exhibiting higher phenolic content compared to aqueous extracts as supported in Kaur \& Kapoor [21]. In garlic samples, higher phenolic content in aqueous samples may be due to the presence of S-allyl-cysteines (SACs) that are extracted in aqueous solutions unlike the organosulfur volatile allicin [35]. Research [28] [36] [37] suggests that the inhibitory potential of ginger is correlated to phenolic content by the presence of gingerols and shogals. These select extracts correlated with high radical scavenging and reducing ability of DPPH, FRAP, and TEAC assays.

\section{Conclusion}

Malfunctions in glucose and lipid metabolism serve as contributing factors to pathogenesis of Type 2 Diabetes. Post-prandial blood glucose levels serve a 
primary threat in enhancing the development of diabetic complications. As a result, carbohydrate metabolizing enzymes, $\alpha$-amylase and $\alpha$-glucosidase and inhibition of lipase has gained interest in controlling blood glucose levels. In this study heat-treated garlic, turmeric, and ginger displayed anti-diabetic potential by inhibiting critical carbohydrate and lipid-metabolizing enzymes, $\alpha$-amylase $\alpha$-glucosidase, and lipase. Turmeric, garlic and ginger also displayed antioxidative potential through reducing and scavenging free radicals. Therefore, these spices could be used as a health promoting food additive in the food industry.

\section{Acknowledgements}

Funding for this research was provided by the Alabama Agricultural Experimental Research Station, Title III, and USDA/CBG Grant.

\section{References}

[1] Lako, J., Trenerry, V., Wahlqvist, M., Wattanapenpaiboon, N., Sotheeswaran, S. and Premier, R. (2007) Phytochemical Flavonols, Carotenoids and the Antioxidant Properties of a Wide Selection of Fijian Fruit, Vegetables and Other Readily Available Foods. Journal of Food Chemistry, 101, 1727-1741. https://doi.org/10.1016/j.foodchem.2006.01.031

[2] Mofleh, I. (2010) Spices Herbal Xenobiotics and the Stomach: Friends or Foes? World Journal of Gastroenterology, 16, 2710-2719. https://doi.org/10.3748/wjg.v16.i22.2710

[3] Sen, S., Chakraborty, R., Sridhar, C., Reddy, Y. and De, B. (2010) Free Radicals, Antioxidants, Diseases and Phytomedicines: Current Status and Future Prospect. International Journal of Pharmaceutical Sciences Review and Research, 3, 91-100.

[4] Iyer, A., Panchal, S., Poudyal, H. and Brown, L. (2009) Potential Health Benefits of Indian Spices in the Symptoms of Metabolic Syndrome: A Review. Indian Journal of Biochemistry \& Biophysics, 46, 467-481.

[5] Bazzano, L.A., Li, T.Y., Joshipura, K.J. and Hu, F.B. (2008) Intake of Fruit, Vegetables, and Fruit Juices and Risk of Diabetes in Women. Diabetes Care, 31, 1311-1317. https://doi.org/10.2337/dc08-0080

[6] Carter, P., Gray, L.J., Troughton, J., Khunti, K. and Davies, M.J. (2010) Fruit and Vegetable Intake and Incidence of Type 2 Diabetes Mellitus: Systematic Review and Meta-Analysis. BMJ, 341, c4229. https://doi.org/10.1136/bmj.c4229

[7] Srinivasan, K. (2005) Plant Foods in the Management of Diabetes Mellitus: Spices as Beneficial Antidiabetic Food Adjuncts. International Journal of Food Sciences and Nutrition, 56, 399-414. https://doi.org/10.1080/09637480500512872

[8] Asif, M. (2011) The Role of Fruits, Vegetables, and Spices in Diabetes. International Journal of Nutrition, Pharmacology, Neurological Diseases, 1, 27-35. https://doi.org/10.4103/2231-0738.77527

[9] Madkor, H., Mansour, S. and Raman, G. (2011) Modulatory Effects of Garlic, Ginger, Turmeric and Their Mixture on Hyperglycemia, Dyslipidemia and Oxidative Stress in Streptozotocin-Nicotinamide Diabetic Rats. British Journal of Nutrition, 105, 1210-1217. https://doi.org/10.1017/S0007114510004927

[10] Rawson, A., Patras, A. Tiwari, B.K., Noci, F., Koutchma, T. and Brunton, N. (2011) Effect of Thermal and Non Thermal Processing Technologies on the Bioactive Content of Exotic Fruits and Their Products: Review of Recent Advances. Food Research International, 44, 1875-1887. https://doi.org/10.1016/j.foodres.2011.02.053 
[11] Dewanto, V., Wu, X., Adom, K.K. and Liu, R.H. (2002) Thermal Processing Enhances the Nutritional Value of Tomatoes by Increasing Total Antioxidant Activity. Journal of Agricultural and Food Chemistry, 50, 3010-3014. https://doi.org/10.1021/jf0115589

[12] Li, W., Pickard, M.D. and Beta, T. (2007) Effect of Thermal Processing on Antioxidant Properties of Purple Wheat Bran. Food Chemistry, 104, 1080-1086. https://doi.org/10.1016/j.foodchem.2007.01.024

[13] Singleton, V., Orthofer, R. and Lamuela-Raventós, R. (1999) Analysis of Total Phenols and Other Oxidation Substrates and Antioxidants by Means of Folin-Ciocalteu Reagent. Methods in Enzymology, 299, 152-178. https://doi.org/10.1016/S0076-6879(99)99017-1

[14] Marinova, D., Ribarova, F. and Atanassova, M. (2005) Total Phenolics and Total Flavonoids in Bulgarian Fruits and Vegetables. Journal of the University of Chemical Technology Metallurgy, 40, 255-260.

[15] Brand-Williams, W., Cuvelier, M. and Berset, C. (1995) Use of a Free Radical Method to Evaluate Antioxidant Activity. Food Science and Technology, 28, 25-30. https://doi.org/10.1016/S0023-6438(95)80008-5

[16] Benzie, I.F.F. and Strain, J.J. (1999) Ferric Reducing Antioxidant Power Assay: Direct Measure of Total Antioxidant Activity of Biological Fluids and Modified Version for Simultaneous Measurement of Total Antioxidant Power and Ascorbic Acid Concentration. Methods Enzymology, 299, 15-27. https://doi.org/10.1016/S0076-6879(99)99005-5

[17] Miller, N.J., Rice-Evans, C., Davies, M., Gopinathan, V. and Milner, A. (1993) A Novel Method for Measuring Antioxidant Capacity and Its Application to Monitoring the Antioxidant Status in Premature Neonates. Clinical Science, 4, 407-412. https://doi.org/10.1042/cs0840407

[18] Mosmuller, E.W.J., Van Heemst, J.D.H., Van Delden, C.J., Franssen, M.C.R. and Engbersen, J.F.J. (1992) A New Spectrophotometric Method for the Detection of Lipase Activity Using 2, 4-Dinitrophenyl Butyrate as a Substrate. Biocatalysis and Biotransformation, 5, 279-287. https://doi.org/10.3109/10242429209014874

[19] Apostolidis, E., Li, L., Lee, C. and Seeram, N. (2011). In Vitro Evaluation of Phenolic-Enriched Maple Syrup Extracts for Inhibition of Carbohydrate Hydrolyzing Enzymes Relevant to type 2 Diabetes Management. Journal of Functional Foods, 3, 100-106. https://doi.org/10.1016/j.jff.2011.03.003

[20] Szychowski, K. A., Rybczyńska-Tkaczyk, K., Gaweł-Bęben, K., Świeca, M., Karaś, M., Jakubczyk, A. and Gmiński, J. (2018) Characterization of Active Compounds of Different Garlic (Allium sativum L.) Cultivars. Polish Journal of Food and Nutrition Sciences, 68, 73-81. https://doi.org/10.1515/pjfns-2017-0005

[21] Kaur, C. and Kapoor, H. (2002) Anti-Oxidant Activity and Total Phenolic Content of Some Asian Vegetables. International Journal of Food Science and Technology, 37, 153-161. https://doi.org/10.1046/j.1365-2621.2002.00552.x

[22] Panpatil, V., Tattari, S., Kota, N., Nimgulkar, C. and Polasa, K. (2013) In Vitro Evaluation on Antioxidant and Antimicrobial Activity of Ginger, Turmeric, and Garlic. Journal of Pharmacognosy and Phytochemistry, 2, 143-148.

[23] Udu-Ibiam, O., Ogbu, O., Ibiam, U., Nnachi, A., Agah, M., Ukaegbu, C., Chukwu, O., Agumah, N. and Ogbu, K. (2014) Phytochemical and Antioxidant Analyses of Selected Edible Mushrooms, Ginger, and Garlic from Ebonyi State, Nigeria. Journal of Pharmacy and Biological Sciences, 9, 86-91. https://doi.org/10.9790/3008-09348691 
[24] Nuutila, A., Puupponen-Pimiä, R., Aarni, M. and Oksman-Caldentey, K. (2003) Comparison of Antioxidant Activities of Onion and Garlic Extracts by Inhibition of Lipid Peroxidation and Radical Scavenging Activity. Journal of Food Chemistry, 81, 485-493. https://doi.org/10.1016/S0308-8146(02)00476-4

[25] Oboh, G., Akinyemi, A. and Ademiluyi, A. (2012) Inhibition of $\alpha$-Amylase and $\alpha$-Glucosidase Activity by Ethanolic Extracts of Telfairiaoccidentalis (Fluted Pumpkin) Leaf. Asian Pacific Journal of Tropical Biomedicine, 2, 733-738. https://doi.org/10.1016/S2221-1691(12)60219-6

[26] Flores-Sanchez, I. and Gang, D. (2013) Inhibition of Hydroxycinnamoyl-CoA Thioesterases in Ginger (Zingiber officinale Rosc.) and Turmeric (Curcuma longa L.) by Lipase Inhibitors. Plant Physiology and Biochemistry, 72, 46-53. https://doi.org/10.1016/j.plaphy.2013.02.012

[27] Ponnusamy, S., Zinjarde, S., Bhargava, S., Rajamohanan, P.R. and RaviKumar, A. (2012) Discovering Bisdemethoxycurcumin from Curcuma longa Rhizome as a Potent Small Molecule Inhibitor of Human Pancreatic $\alpha$-Amylase, a Target for Type 2 Diabetes. Food Chemistry, 135, 2638-2642. https://doi.org/10.1016/j.foodchem.2012.06.110

[28] Rani, M.P., Padmakumari, K.P., Sankarikutty, B., Cherian, O.L., Nisha, V.M., et al. (2011) Inhibitory Potential of Ginger Extracts against Enzymes Linked to Type 2 Diabetes, Inflammation and Induced Oxidative Stress. International Journal of Food Sciences and Nutrition, 62, 106-110. https://doi.org/10.3109/09637486.2010.515565

[29] Katekhaye, S. and Nagmoti, D. (2013) $\alpha$-Glucosidase and $\alpha$-Amylase Inhibitory Activities of Pithecellobiumdulce Bark and Leaves. Phytopharmacology, 4, 123-130.

[30] Nickavar, B. and Yousefian, N. (2009) Inhibitory Effects of Six Allium Species on a-Amylase Enzyme Activity. Iranian Journal Pharm Research, 8, 53-57.

[31] Karamac, M. and Amarowicz, R. (1996) Inhibition of Pancreatic Lipase by Phenolic Acids-Examination in Vitro. Zeitschrift für Naturforschung, 51, 903-905.

[32] Gargouri, Y., Moreau, H., Jain, M., Haas, G. and Verger, R. (1989) Ajoene Prevents Fat Digestion by Human Gastric Lipase in Vitro. Biochimica et Biophysicaacta (BBA) - Lipids and Lipid Metabolism, 1006, 137-139. https://doi.org/10.1016/0005-2760(89)90335-4

[33] Tang, G., Li, X. and Zhang, H. (2008) Antidiabetic Components Contained in Vegetables and Legumes. Molecules, 13, 1189-1194. https://doi.org/10.3390/molecules13051189

[34] Rajasree, C., Rajamoham, T. and Augusti, K. (1999) Biochemical Effects of Garlic Protein on Lipid Metabolism in Alcohol Fed Rats. Indian Journal of Experimental Biology, 37, 243-247.

[35] Amagase, H. and Milner, J. (1993) Impact of Various Sources of Garlic and Their Constituents on 7,12-dimethylbenz[a]anthracene Binding to Mammary Cell DNA. Carcinogenesis, 14, 1627-1631. https://doi.org/10.1093/carcin/14.8.1627

[36] Shidfar, F., Khandouzi, N. and Hosseini, S. (2015) The Effect of Ginger (Zingiber officinale) on Glycemic Markers in Patients with Type 2 Diabetes. Journal of Complementary and Integrative Medicine, 12, 165-170.

https://doi.org/10.1515/jcim-2014-0021

[37] Hosseini, S., Jahandidea, A. and Mehrabani, D. (2015) Effect of Alcoholic Extract of Ginger during Fetal Life and Breastfeeding on Serum Level of Testosterone, LH, FSH and Spermatogenic Cells Line in Male Mature Offspring Rats. Journal of Gorgan University of Medical Sciences, 17, Pe29-Pe34. 